\title{
Analysis of ambient airborne mycoflora around Curzon hall campus, University of Dhaka, Bangladesh
}

\author{
Md. Nazim Uddin ${ }^{1}$, Gulshan Ara Latifa ${ }^{1}$, Ahmad Kamruzzaman Majumder ${ }^{1}$, Shamim Shamsi ${ }^{2}$ and \\ Abdullah Al Nayeem ${ }^{1}$ \\ ${ }^{I}$ Center for Atmospheric Pollution Studies (CAPS), Department of Environmental Science, Stamford University Bangladesh, \\ Dhaka-1209, Bangladesh \\ ${ }^{2}$ University of Dhaka, Bangladesh
}

Received 22 November 2019/Accepted 20 December 2019

\begin{abstract}
The indoor and outdoor air is an important source of aeroallergens and pathogens. Monthly samplings were recorded during September to November 2018 to investigate the airborne mycoflora concentration in Curzon hall campus, University of Dhaka. The fungal colonies developed in Potato Dextrose Agar (PDA) media were isolated from four different locations in the morning, noon and evening in monthly intervals. A total number of counted fungal colonies were 2,681 in which 924, 928 and 829 colonies were found in the morning, noon and evening time, respectively. Among the identified fungi, Aspergillus spp. was one of the most predominant genera in all the stations over the study period followed by Penicillium spp. Alternaria spp., Curvularia spp., Fusarium spp., Rhizopus spp. and Trichoderma. The identified fungi belonged to eight genera under the class Ascomycetes, Zygomycetes and Deuteromycetes. Among the fungal isolates, Alternaria spp., Aspergillus spp., Curvularia spp., Fusarium spp., Penicillium spp. and Rhizopus spp. were previously reported as pathogenic to plants and/or humans and strongly allergenic to human being.
\end{abstract}

Keywords: Mycoflora, Airborne pathogens, Genera, Meteorology.

\section{INTRODUCTION}

Airborne particles are found everywhere in nature (1). The atmosphere of earth contains airborne viruses, bacteria, protozoa, pollen grains, different propagules and vegetative cells of algae, fungi, lichens, bryophytes and pteridophytes. Microbial quality and quantity of air depends on seasons, time and locations (2). Fungal spores play a significant role in childhood asthma, allergies, mycotoxicity and infections in human and animals $(3,4)$. About $20 \%$ of human population is easily sensitized by normal concentrations fungal spore (up to $10^{6}$ spores $/ \mathrm{m}^{3}$ ) and all fungal spores should be regarded as potentially allergenic (5). Airborne fungi are considered as one of the indicators of atmospheric bio-pollution (6). Numerous plant diseases such as rusts, smuts, mildews, leaf spots, etc. are also caused by airborne fungi (7-9).

Occurrence of fungal spores in the air fluctuate in different seasons with the variations in the weather conditions. Warm and dry weather favors the development, sporulation and dispersal of conidia of Cladosporium spp., Epicoccum spp. and Alternaria spp. The highest concentration of conidia of those genera usually occurs at noon and afternoon (2). It can vary with vegetation types. Excessive concentrations of Alternaria spp. spores were noted at the harvesting seasons $(10,11)$. Surveys on these aspects have been made in different countries of the world following impaction or sedimentation method (12-15). The sedimentation method is still quite popular in India and some other countries as it is cheap, simple and recommended by Polish Standards (15-17). Nowadays, people are more concerned about the gaseous and particulate pollution in the atmosphere. But, microbial pollutants are also important as they have severe impacts on human health.

The present investigation has therefore, been undertaken to study the monthly distribution pattern of mycoflora in the air of the Curzon hall campus, University of Dhaka, Bangladesh.

\section{MATERIALS AND METHODS}

Sampling areas. Four locations of Curzon hall campus area, University of Dhaka were selected for the sampling of air borne fungal spores from

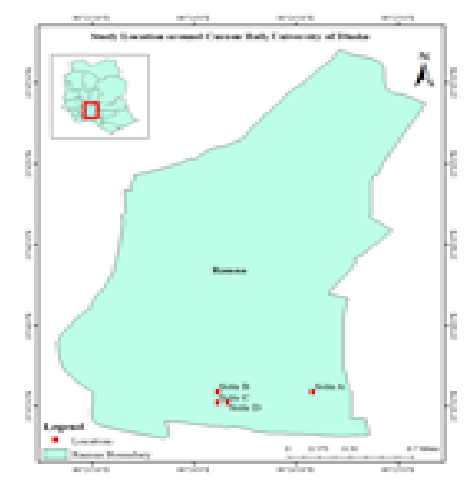

Figure 1. Map showing the Study Area

*Corresponding Author: Mailing address. Dr. Ahmad Kamruzzaman Majumder, Professor, Department of Environmental Science, Stamford University Bangladesh, Dhaka-1209, Bangladesh; E-mail: kamrul_sub@hotmail.com. 


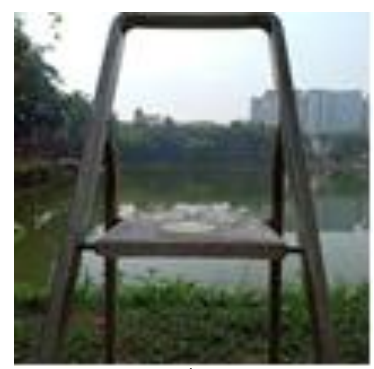

A

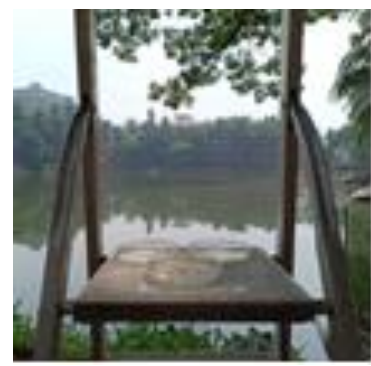

B

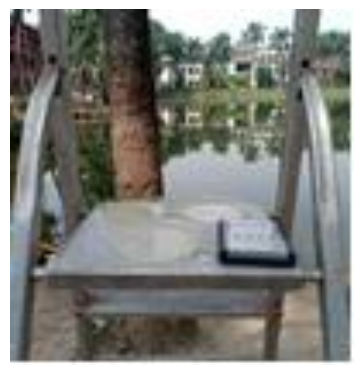

C

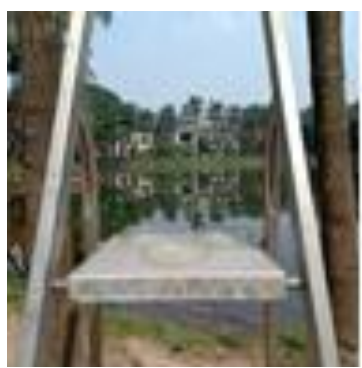

D

September to November 2018 (Figure 1). The sampling sites were, A: Zoology department side $\left(23^{0} 43\right.$ '35" N $90^{0} \quad 24$ ' $35^{\prime}$ ” E), B: Fishery department side $\left(23^{0} 43^{\prime} 35^{\prime}\right.$ ' N $90^{\circ}$ 24' 07” E), C: Dr. Muhammad Shahidullah hall side $\left(23^{0} 43\right.$ ' $31^{\prime \prime} \mathrm{N} 90^{\circ} 24^{\prime} 07$ " E), D: Fazlul Huq Muslim hall mosque side $\left(23^{0} 43^{\prime} 31^{\prime \prime} \mathrm{N} 90^{\circ} 24^{\prime} 10^{\prime \prime} \mathrm{E}\right)$. Figure 2 shows the real time data collection image in the study area.

Sampling. Culture plates were exposed for 10 minutes in the morning 8-9 am, noon from 12-1 pm and evening from 4-5 pm. The sampling was done during the three months from September 2018 to November 2018. Gravity plate sampling method was followed for the isolation of fungi from the selected locations. Potato Dextrose Agar (PDA) medium was used for the isolation of fungi at monthly intervals where $50 \%$ lactic acid was added to limit bacterial contamination. The Petri plates were exposed for 10 minutes in the morning, noon and evening of the same day to avoid the over load of fungal spores on the surface of the culture medium. The Petri plates containing culture medium were exposed at the height of 1 meter from the ground level on a tetrapod stand. Three replicates were maintained for each culture medium.

Isolation of mycoflora. The exposed Petri plates containing PDA media

were taken into the laboratory and incubated at $25 \pm 2^{\circ} \mathrm{C}$ for five days. The growth of the mycoflora on the culture plates were examined daily and the colonies which born spores were examined under microscope after further incubation. Those fungi which did not produce reproductive spores within 7 days were incubated for 10 days or more. The colonies developed on the culture media were counted. The isolation was done by transferring a bit or a single spore into the sterile Petri plates containing PDA medium. Pure culture of each fungal isolates was done by dilution plate method and single spore culture technique. Pure cultures were stored at $4^{\circ} \mathrm{C}$ in slant medium for further studies. The fungal colonies developed on the culture media were examined under microscope and identified based on their morphological structure. Percentage of abundance and frequency distribution of the fungal colonies were calculated by adopting the formula of Pathak (18).

\section{RESULTS AND DISCUSSION}

Incidence and percent frequency distribution of fungi during the morning between September 2018 and

Table 2. Incidence and percent frequency distribution of fungal genera in PDA medium collected in the morning from different locations between September and November 2018

\begin{tabular}{|c|c|c|c|c|c|c|c|c|}
\hline \multirow{2}{*}{$\begin{array}{l}\text { Fungal } \\
\text { Genera }\end{array}$} & \multicolumn{5}{|c|}{$\begin{array}{l}\text { No. of fungal colonies in PDA medium } \\
\text { from different locations }\end{array}$} & \multirow{2}{*}{ 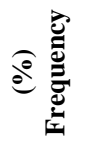 } & \multirow{2}{*}{$\stackrel{\bar{\Xi}}{\sum_{\Sigma}}$} & \multirow{2}{*}{ 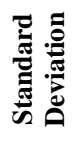 } \\
\hline & A & B & $\mathrm{C}$ & $\mathrm{D}$ & Total & & & \\
\hline Alternaria & 33 & 23 & 36 & 40 & 132 & 14.2 & 33 & 7.2 \\
\hline Aspergillus & 74 & 87 & 54 & 41 & 256 & 27.7 & 64 & 20.5 \\
\hline Curvularia & 22 & 32 & 23 & 13 & 90 & 9.7 & 22.5 & 7.7 \\
\hline Fusarium & 18 & 27 & 22 & 20 & 87 & 9.4 & 21.8 & 3.8 \\
\hline Penicillium & 46 & 58 & 55 & 61 & 220 & 23.1 & 55 & 6.4 \\
\hline Rhizopus & 18 & 20 & 16 & 16 & 70 & 7.8 & 17.5 & 1.9 \\
\hline $\begin{array}{c}\text { Sterile } \\
\text { mycelium }\end{array}$ & 8 & 7 & 5 & 13 & 33 & 3.7 & 8.2 & 3.4 \\
\hline Trichoderma & 6 & 9 & 7 & 14 & 36 & 3.1 & 9 & 3.5 \\
\hline Total & 225 & 263 & 218 & 218 & 924 & 100 & 28.8 & 6.8 \\
\hline
\end{tabular}

Sites, A: Zoology department side, B: Fishery department side, C: Dr. Muhammad Shahidullah hall side, D: Fazlul Huq Muslim hall mosque side

Table 1. Incidence and percent frequency distribution of fungal genera in PDA medium collected during noon from different locations between September and November 2018

\begin{tabular}{|c|c|c|c|c|c|c|c|c|}
\hline \multirow{2}{*}{$\begin{array}{l}\text { Fungal } \\
\text { Genera }\end{array}$} & \multicolumn{5}{|c|}{$\begin{array}{l}\text { No. of fungal colonies in PDA medium } \\
\text { from different locations }\end{array}$} & \multirow{2}{*}{ ฮી } & \multirow{2}{*}{$\stackrel{\Xi}{\sum^{\circledR}}$} & \multirow{2}{*}{ 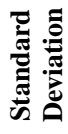 } \\
\hline & $\mathrm{A}$ & B & $\mathrm{C}$ & $\mathrm{D}$ & Total & & & \\
\hline Alternaria & 35 & 25 & 42 & 44 & 146 & 15.7 & 37 & 8.5 \\
\hline Aspergillus & 65 & 75 & 56 & 43 & 239 & 25.8 & 60 & 13.5 \\
\hline Curvularia & 26 & 34 & 21 & 15 & 96 & 10.3 & 24 & 8 \\
\hline Fusarium & 22 & 28 & 24 & 20 & 94 & 10.1 & 24 & 3.4 \\
\hline Penicillium & 42 & 59 & 57 & 63 & 221 & 23.8 & 55 & 9.1 \\
\hline Rhizopus & 19 & 18 & 18 & 15 & 70 & 7.54 & 18 & 1.7 \\
\hline $\begin{array}{c}\text { Sterile } \\
\text { mycelium }\end{array}$ & 9 & 6 & 6 & 12 & 33 & 3.56 & 8.3 & 2.8 \\
\hline Trichoderma & 7 & 7 & 5 & 10 & 29 & 3.13 & 7.3 & 2 \\
\hline Total & 225 & 252 & 229 & 222 & 928 & 100 & 29.2 & 6.2 \\
\hline
\end{tabular}

Sites, A: Zoology department site, B: Fishery department site, C: Dr. Muhammad Shahidullah hall site, D: Fazlul Huq Muslim hall mosque site 
November 2018 is presented in Table 1. The table showed that a total of 924 fungal colonies were isolated in the morning out of which the highest number of colonies were Aspergillus spp. (256) followed by Penicillium spp. (220) and Alternaria spp. (132). The lowest numbers of fungal colonies were recorded for sterile mycelium (33).

Table 2 showed the results of fungal isolates at noon. allergenic, bad physical condition, tiredness, headaches, vertigo, decrease of concentration, memory and intellectual work ability and so on (17).

Present study revealed that maximum fungal colonies were found in the month of October (Table 4). It was observed that spore contents were

Table 3. Incidence and percent frequency distribution of fungal genera in PDA medium collected in the evening from different locations during September to November 2018

\begin{tabular}{|c|c|c|c|c|c|c|c|c|}
\hline \multirow{2}{*}{$\begin{array}{l}\text { Fungal } \\
\text { Colonies }\end{array}$} & \multicolumn{5}{|c|}{$\begin{array}{l}\text { No. of fungal colonies in PDA medium } \\
\text { from different locations }\end{array}$} & \multirow{2}{*}{ తి } & \multirow{2}{*}{$\stackrel{\Xi}{\Xi}$} & \multirow{2}{*}{ } \\
\hline & A & B & $\mathrm{C}$ & $\mathrm{D}$ & Total & & & \\
\hline Alternaria & 32 & 21 & 41 & 41 & 135 & 16 & 34 & 9.5 \\
\hline Aspergillus & 42 & 53 & 52 & 41 & 188 & 23 & 47 & 6.3 \\
\hline Curvularia & 21 & 29 & 18 & 17 & 85 & 10 & 21 & 5.4 \\
\hline Fusarium & 19 & 27 & 22 & 19 & 87 & 10 & 22 & 3.7 \\
\hline Penicillium & 46 & 51 & 49 & 61 & 207 & 25 & 52 & 6.5 \\
\hline Rhizopus & 17 & 19 & 13 & 13 & 62 & 7.5 & 16 & 3 \\
\hline $\begin{array}{c}\text { Sterile } \\
\text { mycelim }\end{array}$ & 8 & 5 & 7 & 15 & 35 & 4.2 & 8.8 & 4.3 \\
\hline Trichoderma & 6 & 6 & 6 & 12 & 30 & 3.6 & 7.5 & 3 \\
\hline Total & 191 & 211 & 208 & 219 & 829 & 100 & 26.1 & 5.4 \\
\hline
\end{tabular}

Sites, A: Zoology department side, B: Fishery department side, C: Dr. Muhammad Shahidullah hall side, D: Fazlul Huq Muslim hall mosque side.

Table 4. Climate factors and total number of fungal colonies

\begin{tabular}{|c|c|c|c|c|c|c|c|c|c|c|}
\hline \multirow[b]{2}{*}{ Month } & \multicolumn{3}{|c|}{ Temperature $\left({ }^{\circ} \mathrm{C}\right)$} & \multicolumn{3}{|c|}{$\begin{array}{c}\text { Relative Humidity } \\
(\%)\end{array}$} & \multirow{2}{*}{ 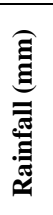 } & \multicolumn{3}{|c|}{ Total Fungal Colony } \\
\hline & 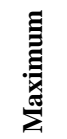 & 志 & $\underset{\Xi}{\Xi}$ & 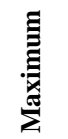 & 声 & 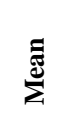 & & 兰 & $\begin{array}{l}\text { ह̊ } \\
\text { Z }\end{array}$ & 㝵 \\
\hline September & 32.7 & 25.3 & 29 & 83.4 & 52.9 & 68.15 & 255 & 286 & 269 & 248 \\
\hline October & 32.6 & 24.6 & 28.6 & 70.7 & 49.7 & 60.2 & 135 & 341 & 367 & 368 \\
\hline November & 28.8 & 18.6 & 23.7 & 74.6 & 47.1 & 60.85 & 25 & 297 & 292 & 213 \\
\hline
\end{tabular}

A total of 928 fungal colonies were recorded from four different locations. Out of 928, the highest number was recorded in case of Aspergillus spp. (239) followed by Penicillium spp. (221) and Alternaria spp. (146). Moreover, Trichoderma spp. (29) was the lowermost in number of colonies.

Table 3 showed the frequency of fungal isolates found in the evening. A total of 829 fungal colonies were recorded from four selected locations. Out of 829 , the highest number was recorded in case of Penicillium spp. (207), followed by Aspergillus spp. (188) and Alternaria spp. (135). Here, Trichoderma spp. (30) was the lowest in number of colonies.

Abdullah et al., (2019) shows that, at Malnicherra tea estate of Sylhet district, Aspergillus fumigatus showed the maximum percentage followed by Aspergillus flavus, Curvularia interseminata, Aspergillus niger (19). A study in Tehran shows the predominant genus identified in air was Penicillium (34.88\% of total airborne fungi) during the study period (20). Epidemiological studies showed that high concentration of microorganisms in the air can causes comparatively less in the month of September. It might be due to high temperature and humidity. In addition, high rainfall leads to decrease the fungal colony as continuous waterfall usually washes out the spores. Another study revealed that, Alternaria, Aspergillus and Penicillium were found in higher concentration during dry winter seasons (21). Vegetation types, warm and dry weather always attribute to development, sporulation and dispersal of fungal colonies in the ambient air. The identified fungi belonged to eight genera under the classes of Ascomycetes, Zygomycetes and Deuteromycetes. Among the different genera of fungi, Alternaria, Aspergillus, Curvularia, Fusarium, Penicillium and Rhizopus were reported as pathogenic to plants and/or humans and were proved to be strong allergen to human being.

\section{CONCLUSION}

Among the eight identified fungi, Aspergillus was one of the most prevalent genera in all the four locations over the study period. Presence of fungal 
spores in the air varied from month to month because of the variation of weather elements. This study contributes to our understanding of airborne spores and there distribution pattern in the Dhaka University campus. Regular monitoring of airborne fungi can be helpful in the prevention of fungal allergic diseases and related complications especially in over-crowded area in Dhaka city.

\section{ACKNOWLEDGEMENTS}

The authors are thankful to the Department of Botany, University of Dhaka for providing all laboratory facilities for carrying out the present study and obliged to Md. Sarowar Hosen, Lecturer, Department of Botany, University of Dhaka for his kind assistance during this work. The authors express their cordial appreciations to Taniya Sultalana, Tahera khatun, Abdullah Arpon, Dr. Abdullah Al Noman and junior research fellows of the laboratory of Mycology and Plant Pathology, Department of Botany, University of Dhaka for their dedicated help, encouragement and co-operation.

\section{REFERENCES}

1. Pavan R and Manjunath K. 2014. Qualitative analysis of indoor and outdoor airborne fungi in Cowshed. J. Mycol. 2 014: Article ID 985921 , 8 pages.

2. Lighthart B. 2000. Mini-review of the concentration variations found in the alfresco atmospheric bacterial populations. Aerobiologia 16:7-16.

3. Burge HA. 1985. Fungus allergens. Clin. Rev. Allergy Immunol. 3:319329.

4. Aimanianda V, Bayrz J, Bozza S, Kniemeyer O and Perruccio K. 2010. Clever cloak prevents immune recognition of air borne fungal spores. 4th advances against Aspergillosis, Asp. Newsl. 460:1117-1123.
5. Burge HA. 2001. Fungi: toxic killers or unavoidable nuisances? Ann. Allergy. Asthma. Immunol. 87:52-56.

6. Kakde UB, Kakde HU and Saoji AA. 2001. Seasonal variation of fungal propagules in a fruit market environment, Nagpur (India). Aerobiologia 17:177-182.

7. Kendrick B. 2000. The fifth kingdom. 3rd ed. Focus Publishing, R. Pullins Co. Newburyport MA 01950, USA. pp. XI+373.

8. Cvetnić Z and Pepeljnjak S. 1997. Distribution and mycotoxinproducing ability of some fungal isolates from the air. Atmos. Environ. 31:491-495.

9. Black PN, Udy AA and Brodie SM. 2000. Sensitivity to fungal allergens is a risk factor for life-threatening asthma. Allergy 55:501-504.

10. Chakraborty PS, Gupta-Bhattacharya and Chanda S. 2003. Aeromycoflora of an agricultural farm in West Bengal, India:A five-year study. Grana 42:248-254.

11. Kasprzyk I. 2008. Aeromycology- main research fields of interest during the last 25 years. Ann. Agric. Environ. Med. 15:1-7.

12. Li De-Wei and Kendrick B. 1995. A year-round comparison of fungal spores in indoor and outdoor air. Mycologia 87:190-195.

13. Khan ZU, Khan MAY, Chady R and Sharma PN. 1999. Aspergillus and other moulds in the air of Kuwait. Mycopathologia 146:25-32.

14. Ianovici N and Tudorica D. 2009. Aeromycoflora in outdoor environment of Timisoara City (Romania). Not. Sci. Biol. 1:21-28.

15. Sharma K. 2011. Comparative study of aeromycoflora in relation to soil mycoflora of Darjeeling tea garden, India. Recent Res. Sci. Technol. 3:84-86.

16. Fleischer RM, Bober-Gheek B, Bortkiewcz O and Rusiecka-Ziolkowska J. 2006. Microbiological control of airborne contamination in hospitals. Indoor and Built Environ. 15:53-56.

17. Sekulska M, Stryjakowska, Piotraszewska-Pajak A, Szyszka A, Nowicki M and Filipiak M. 2007. Microbiological quality of indoor air in university room. Pol. J. Environ. Stud. 16:623-632.

18. Pathak K. 2012. An extramural aeromycological investigation of dental college hospital associated environment. Int. J. Environ. Sci. 2:19521961 .

19. Abdullah SM, Iftekhar A, Mohammad OU, Rayhan U, Rahman WU, R. Ara et al. 2019. Studies on Aeromycoflora in Different Tea Estates of Sylhet. Int. Adv. Res. J. Sci. Eng. Technol. 6: 1-7

20. Hoseini M, Jabbari H, Naddafi K, Nabizadeh R, Rahbar M, Yunesian M et al. 2013. Concentration and distribution characteristics of airborne fungi in indoor and outdoor air of Tehran subway stations. Aerobiologia. 29:355-63.

21. Juglul A, Hossain KS and Bashar MA. 2013. Aeromycoflora of the Dhaka University campus. Bangladesh J. Bot. 42:273-278. 